\title{
NUMERICAL MODELLING OF EXTRUSION PROCESS IN SUPERPLASTIC FLOW RANGE
}

\section{INTRODUCTION}

Increased plasticity of some metals and alloys in metal forming processes can be achieved if several conditions are fulfilled, including strain rate, temeprature and frictional conditions in the contact surface metal/tools [3]. Temperature of deformation usually exceeds recrystalization point, thus, a constitutive description of flow stress has the form [1]

$$
\sigma=k \cdot \varepsilon^{n} \cdot \dot{\varepsilon}^{m}
$$

where:

$k$ - factor of proportionality characteristic for a given material,

$\varepsilon-$ stands for strain,

$\dot{\varepsilon}-$ strain rate.

Parameters $n$ and $m$, respectively, describe sensitivity on strain and strain rate. In superplastic deformation of high importance is factor $\dot{\varepsilon}^{m}$ as it indicates the strong dependence of flow stress on strain rate.

The phenomenon of large deformations, reached at relatively low values of stresses, is obtained for low strain rates. For that reason, superplasticity effect is applied in those metal forming processes, where duration of the forming process do not adversely affect overall savings/costs balance of the manufacturing cycle.

It was noticed that providing some technological conditions favours an increase of effectiveness of superplastic deformation process. High sensitivity of material on strain rate has critical influence on strain distribution, and thereby, on the final properties of a finished part. However, so far these days, there are no univocal criteria determining the conditions to be fulfilled in order to obtain the most favourable profile of strain distribution in this relatively simple process of bulk forming.

* Ph.D., ** M.Sc.: Faculty of Metals Engineering and Industrial Computer Science, AGH University of Science and Technology, Cracow, Poland; grzesiak@metal.agh.edu.pl 
In order to determine optimum parameters of a metal forming process physical modelling is performed, however, on account of the special process conditions and duration of the test in the range of superplastic conditions, it would be associated with large costs. Much less costly appear researches involving numerical modelling [4, 7]. Correctness and reliability of this type of modelling is conditioned by the knowledge of physical-chemical and rheological properties of the model material, as well as the parameters of the process concerned. This work is based on assumptions of previously established basic parameters of superplastic deformations, derived from earlier studies [2].

\section{MODELS ASSUMPTIONS AND PROCESS PARAMETERS}

The numerical modelling was carried out for forward and backward extrusion, for alloy $\mathrm{Sn} 38 \mathrm{~Pb}$, which exhibit superplastic capabilities even at room temperature [9]. The study included dependences of extrusion load and distribution of mechanical parameters on process parameters, such as: ram speed $v$, temperature $T$, friction factor $m$, reduction ratio $\lambda$ and die geometry, determined by the angle $2 \alpha$ (Fig. 1 ).

a)

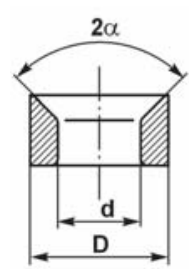

b)

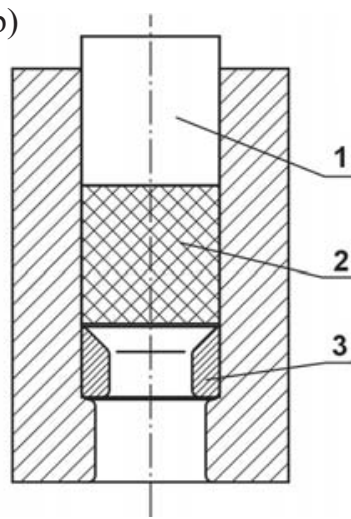

c)

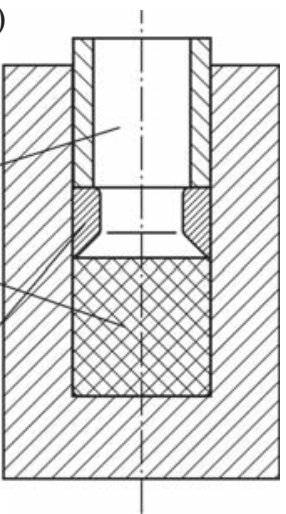

Fig. 1. Scheme of extrusion assembly: a) designation of basic dimensions of dies; b) forward extrusion; c) backward extrusion; 1 - punch, 2 - billet, 3 - die

Reduction ratio is defined as relation of cross-sectional area of a billet $S_{0}$ to the crosssection of extruded bar $S_{k}$

$$
\lambda=\frac{S_{0}}{S_{k}}
$$

Values of the parameters taken into consieration in modelling are set in Table 1. Temperature $T$ refers both to specimens (billet) and tools, as on account on very slow movement of the ram of the hydraulic press, isothermal conditions had to be provided. Simulation involved all the combinations of above-mentioned parameters, which gives total number: $3 \cdot 4 \cdot 3 \cdot 2 \cdot 2 \cdot 2=288$ of variants for analysis.

Geometry and configuration of tools models assumed for simulation of forward and backward extrusion are shown in Figure 1. 
Table 1. Values of parameters for extrusion process simulation

\begin{tabular}{||c|c|c|c|c||}
\hline \hline $\begin{array}{c}\text { Die } \\
\text { angle } \\
2 \alpha\end{array}$ & $\begin{array}{c}\text { Ram } \\
\text { speed } \\
v, \\
\mathrm{~mm} / \mathrm{s}\end{array}$ & $\begin{array}{c}\text { Billet } \\
\text { temperature } \\
T, \\
{ }^{\circ} \mathrm{C}\end{array}$ & $\begin{array}{c}\text { Extrusion } \\
\text { coefficient } \\
\lambda\end{array}$ & $\begin{array}{c}\text { Friction } \\
\text { factor } \\
m\end{array}$ \\
\hline $180^{\circ}$ & 0.01 & 20 & 1.56 & 0.08 \\
\hline $90^{\circ}$ & 0.1 & 40 & 2.78 & 0.4 \\
\hline $60^{\circ}$ & 1.0 & 60 & - & - \\
\hline- & 10 & - & - & - \\
\hline
\end{tabular}

The diameter of a billet, equal to inner diameter of a container was assumed $\mathrm{D}=20 \mathrm{~mm}$, diameter of the die orifice (Fig. 1a) was $d=16 \mathrm{~mm}$ (reduction ratio $\lambda=1.56$ ) and $\mathrm{d}=12 \mathrm{~mm}$ (reduction ratio $\lambda=2.78$ ). The numerical calculations were carried out with a use of commercial code QFORM2D/3D with assumption of visco-plastic model of deformed continuum.

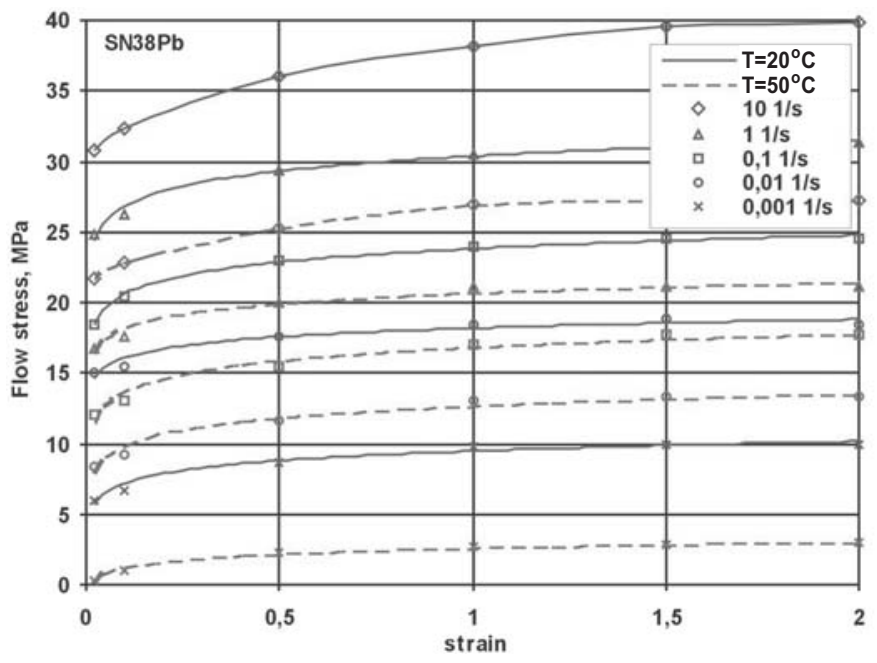

Fig. 2. Characteristics of alloy $\mathrm{Sn} 38 \mathrm{~Pb}$ for temperatures 20 and $50^{\circ} \mathrm{C}$

The rheological description of alloy $\mathrm{Sn} 38 \mathrm{~Pb}$ was introduced into material database in the form of curves of flow stress versus strain for several temperatures and strain rates. The example of the characteristics used in the simulations for temperature 20 and $50^{\circ} \mathrm{C}$ and strain rates ranging form $0.0011 / \mathrm{s}$ to $101 / \mathrm{s}$ is shown in Figure 2. Boundary conditions derived from experimental tests, were assumed in accordance with Table 1.

\section{RESULTS}

Criterion for estimation of the results of performed simulations was a comparision of numerically calculated extrusion load, as well as, distribution of effective strain and effective strain rate. All 288 cases of process conditions were included in the analysis, however, only results obtained for those, of which the effect on the investigated parameters was found essential, were presented in this paper. In Figures 3-5 extrusion load versus forming speed for variable values of die angle, temperature and friction factor was plotted for reduction ratio 1.56 . For reduction ratio 2.78 , similar behaviour of investigated parameters have been reported, yet observed at correspondingly higher level of extrusion load and, therefore, were not presented in this paper. 

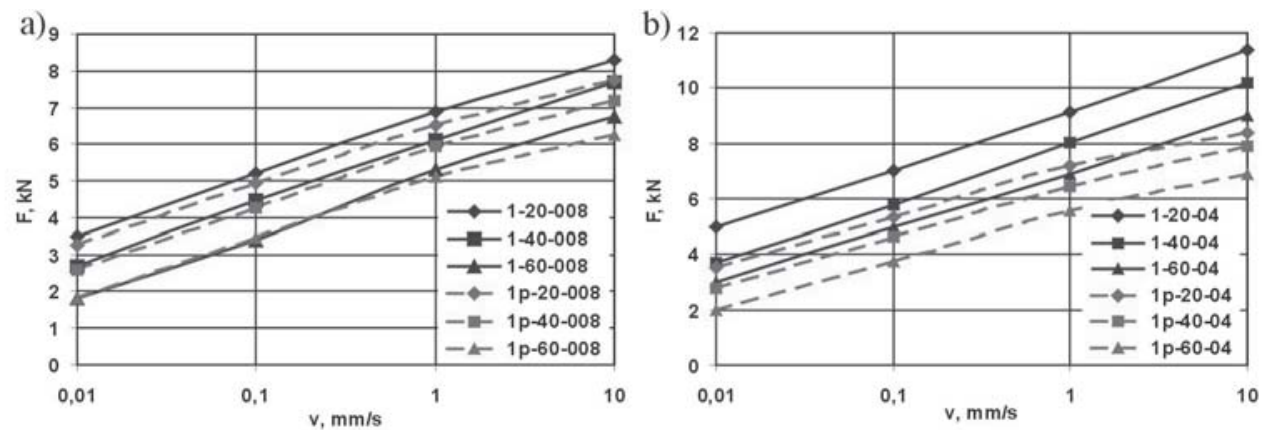

Fig. 3. Plots of load for forward (1) and backward (1p) extrusion versus forming speed $v$ for: $T=20$, 40 and $60^{\circ} \mathrm{C}, 2 \alpha=180^{\circ}, \lambda=1.56$; a) $m=0.08$; b) $m=0.4$
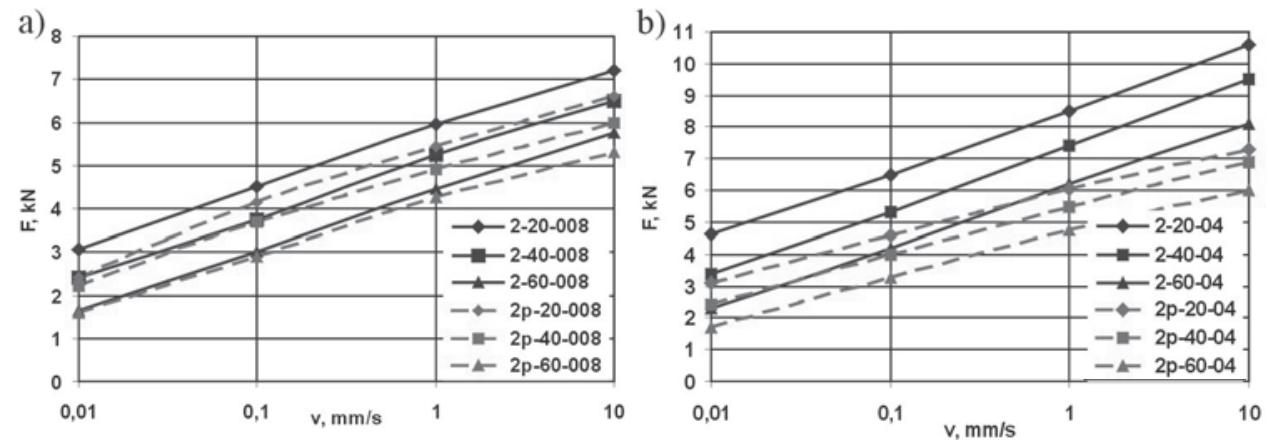

Fig. 4. Plots of load for forward (2) and backward ( $2 p$ ) extrusion versus forming speed $v$ for: $T=20$, 40 and $60^{\circ} \mathrm{C}, 2 \alpha=90^{\circ}, \lambda=1.56$; a) $m=0.08$; b) $m=0.4$
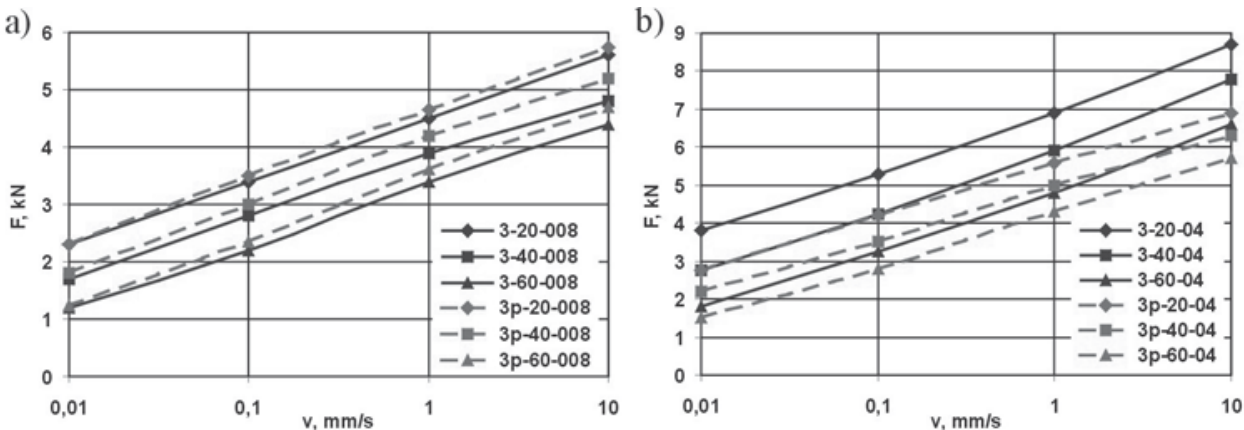

Fig. 5. Plots of load for forward (3) and backward (3p) extrusion versus forming speed $v$ for: $T=20$, 40 and $60^{\circ} \mathrm{C}, 2 \alpha=90^{\circ}, \lambda=1.56$; a) $m=0.08$; b) $m=0.4$

In Figure 6 plots of extrusion load versus punch travel for variable friction factor, forming speed and constant value of die angle $2 \alpha=90^{\circ}$, reduction ratio $\lambda=1.56$ and temperature $\mathrm{T}=40^{\circ} \mathrm{C}$ are presented. Distribution of effective strain for both analysed values of die angle and friction factor are presented in Figure 7 for reduction ratio 1.56, and in Figure 8 for reduction ratio 2.78 , respectively. 

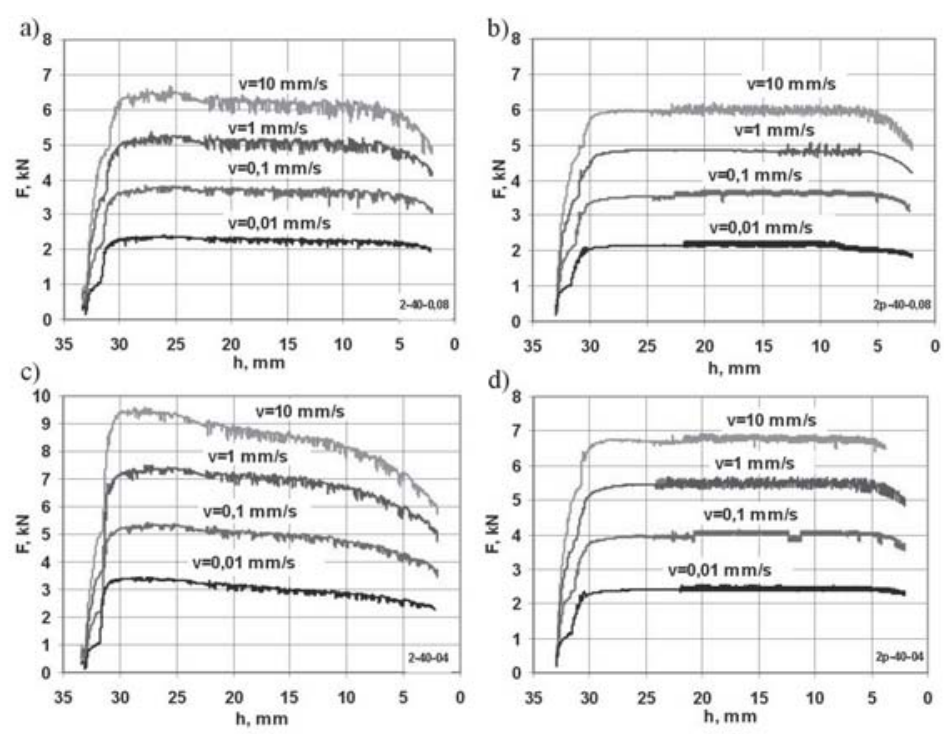

Fig. 6. Extrusion load versus punch travel $h$ for different forming speed $v$ in forward $(a, c)$ and backward $(b, d)$ extrusion process, for $m=0.08(a, b)$ and $0.4(c, d) ; 2 \alpha=90^{\circ}, \lambda=1.56 ; T=40^{\circ} \mathrm{C}$

a)

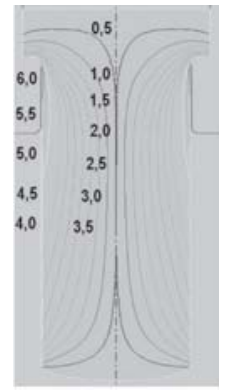

e)

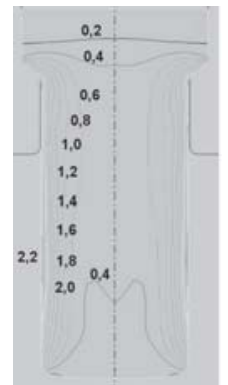

b)

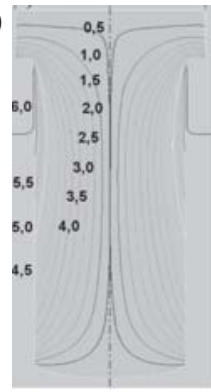

f)

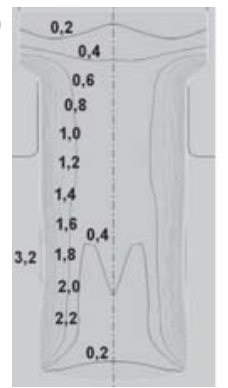

c)

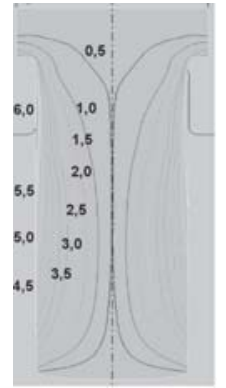

g)

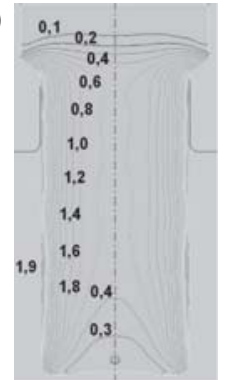

d)

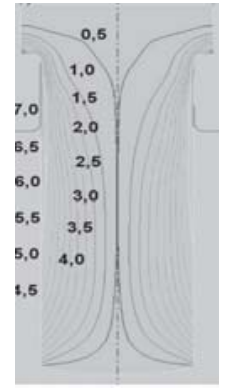

h)

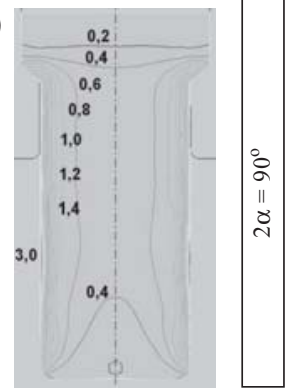

\begin{tabular}{|c|c|c|c|}
\hline $\mathrm{m}=0.08$ & $\mathrm{~m}=0.4$ & $\mathrm{~m}=0.08$ & $\mathrm{~m}=0.04$ \\
\hline \multicolumn{2}{|c|}{$\mathrm{v}=0.01 \mathrm{~mm} / \mathrm{s}$} & \multicolumn{2}{|c|}{$\mathrm{m}=10 \mathrm{~mm} / \mathrm{s}$} \\
\hline
\end{tabular}

Fig. 7. Distribution of effective strain $\varepsilon$ for $\lambda=1.56: 2 \alpha=180^{\circ}(a-d)$ and $90^{\circ}(e-h) ; v=0,01 \mathrm{~mm} / \mathrm{s}$ $(a, b, e, f)$ and $10 \mathrm{~mm} / \mathrm{s}(c, d, g, h) ; m=0.08(a, c, e, g)$ and $0.4(b, d, f, h)$ 
a)

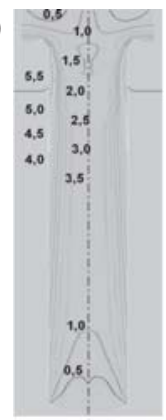

e)

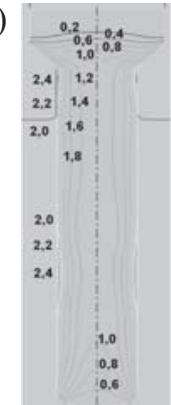

b)

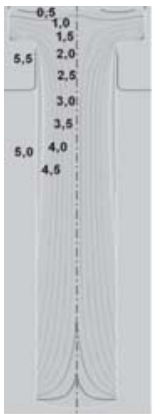

f)

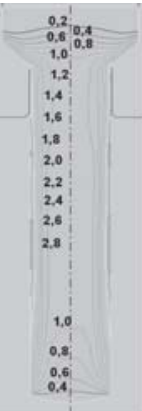

c)

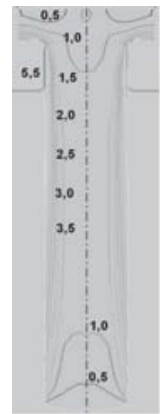

g)

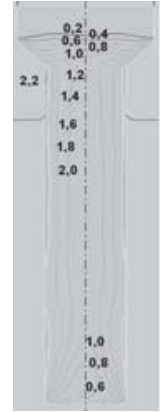

d)

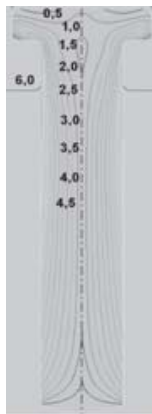

h)

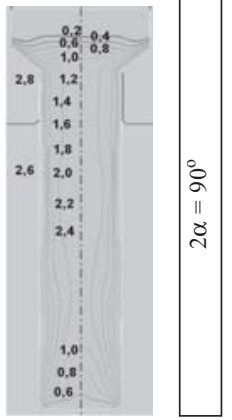

\begin{tabular}{|c|c|c|c|}
\hline $\mathrm{m}=0.08$ & $\mathrm{~m}=0.4$ & $\mathrm{~m}=0.08$ & $\mathrm{~m}=0.04$ \\
\hline \multicolumn{2}{|c|}{$\mathrm{v}=0.01 \mathrm{~mm} / \mathrm{s}$} & \multicolumn{2}{|c|}{$\mathrm{m}=10 \mathrm{~mm} / \mathrm{s}$} \\
\hline
\end{tabular}

Fig. 8. Distribution of effective strain $\varepsilon$ for $\lambda=2.78: 2 \alpha=180^{\circ}(a-d)$ and $90^{\circ}(e-h) ; v=0,01 \mathrm{~mm} / \mathrm{s}$ $(a, b, e, f)$ and $10 \mathrm{~mm} / \mathrm{s}(c, d, g, h) ; m=0.08(a, c, e, g)$ and $0.4(b, d, f, h)$

a)

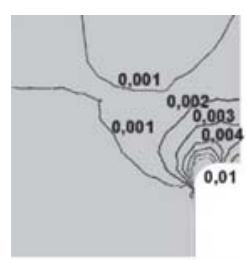

e)

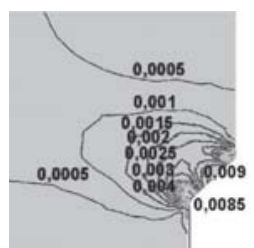

b)

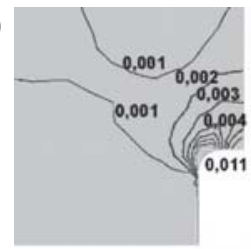

f)

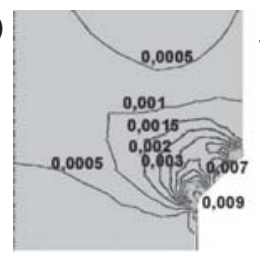

c)

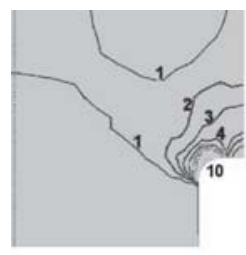

g)

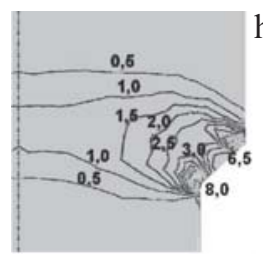

d)

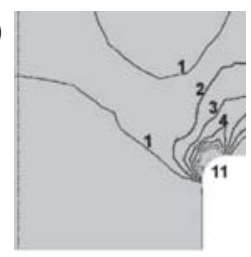

h)

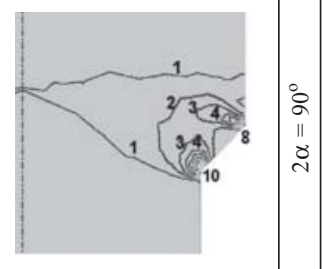

\begin{tabular}{|l|l|l|l|}
\hline $\mathrm{m}=0.08$ & $\mathrm{~m}=0.4$ & $\mathrm{~m}=0.08$ & $\mathrm{~m}=0.04$ \\
\hline \multicolumn{2}{|c|}{$\mathrm{v}=0.01 \mathrm{~mm} / \mathrm{s}$} & \multicolumn{2}{|c|}{$\mathrm{m}=10 \mathrm{~mm} / \mathrm{s}$} \\
\hline
\end{tabular}

Fig. 9. Distribution of effective strain rate $\dot{\varepsilon}$ for $\lambda=2.78: 2 \alpha=180^{\circ}(a-d)$ and $90^{\circ}(e-h) ; v=0,01 \mathrm{~mm} / \mathrm{s}$ $(a, b, e, f)$ and $10 \mathrm{~mm} / \mathrm{s}(c, d, g, h) ; m=0.08(a, c, e, g)$ and $0.4(b, d, f, h)$ 
Distribution of effective strain rate for variable forming speed, die angle and friction factor for reduction ratio 2.78 is shown in Figure 9.

\section{DISCUSSION OF THE RESULTS}

Characteristic and common feature about all of the presented curves of load versus forming speed (Figs 3-5) is near-linear shape of the plots. As the axis $X$ is logarithmic, it means that the load is logarithmic function of velocity, which, in turn, indicates strong dependence of the load on forming speed in the range of low values of velocities, and insignificant effect of forming speed on load in the range of high values. Plots of extrusion load observed at low value of friction factor (Figs 4a-5a) for direct and indirect process differ quite insignificantly, while for higher value of friction factor (Figs $3 b-5 b$ ), the differences are distinct.

The plottings of load versus punch displacement are typical of conventional processes of forward and backward extrusion (Fig. 6). Maximum load for forward extrusion (Figs 6a and $6 \mathrm{c}$ ) in the second stage of the process is higher than that observed for backward extrusion process at the same stage (Figs $6 \mathrm{~b}$ and $6 \mathrm{~d}$ ) for the same boundary conditions. In can be explained by significant contribution of frictional forces acting in the side surface of a container. Indirect extrusion process is characterized by constant value of the load if other conditions remain unchanged. In the last stage of extrusion, the load is the same for both methods of extrusion.

Depicted in Figures 7 and 8 maps of distribution of effective strain indicate significant effect of friction factor, degree of deformation, forming speed and die angle on the metal flow pattern in the analyzed extrusion process. Die geometry has strong effect on the level of maximum strains, which for angle $180^{\circ}$ are twice and/or three times higher than those for $90^{\circ}$. As far as reduction ratio is considered, at its lower value $(\lambda=1.56$, Fig. 7$)$ the differences arise from the die angle: for $180^{\circ}$ the pattern of effective strain isolines is rather uniform, while for $90^{\circ}$ concentration of isolines under the surface indicates localization of deformation in the surface areas - in the core the, distribution of effective strain is much more uniform and the values are lower. As for $\lambda=2.78$ (Fig. 8) effect of friction factor comes up, especially for die angle $180^{\circ}$. Higher value of friction factor results in localization of deformation in the surface areas of the extruded bar, which proves less uniform profile of deformation, and thus, higher gradient of mechanical properties in finished part. Forming at higher speed makes this nonuniformity more apparent (Figs 8c, d, g and h).

With reaching strain rate value equal to threshold of the range of superplastic flow (Figs 9a, b, e and f) or higher (Figs 9c, d, g and h), the metal flow is impeded, which increases the nonuniformity of strain. Such areas are found in the vicinity of fillets of small radii, where changes of flow direction occur. Distribution of effective strain rate is clearly dependent on reduction ratio $\lambda$, and its relation to friction conditions and extrusion speed in the analyzed range of these parameters is rather insignificant.

\section{CONCLUSIONS}

The presented results of numerical modelling of extrusion process in superplasticity conditions indicate strong dependence of the load on the rate of strain, in the range determined by forming speed from 0.01 to $10 \mathrm{~mm} / \mathrm{s}$. The dependence has a logarithmic relation. 
Another important factor which influences the level of extrusion load is friction in the contact surface between deformed metal and tools. For this reason, if there is no possibility to provide low values of friction factor, backward extrusion method is advisable.

Large gradient of deformation, resultant from die geometry is the cause of increase in nonuniformity of deformation for velocities corresponding to threshold values of strain rate for superplastic flow. In order to take advantage of superplastic capabilities of an alloy, which offers obtaining complete filling of die-impressions for extremely complex forgings configurations, appropriate tool velocity should be guaranteed to produce required strain rate in the whole volume of the formed part.

The work was made in the framework of 10.10.110.572

\section{REFERENCES}

[1] Grabski M.: Nadplastyczność strukturalna metali. Śląsk, 1973

[2] GrzesiakJ., SinczakJ., Rusz S.: Structural superplasticity of alloys at increased strain rate. Metallurgy and Foundry Engineering, 26 (2000) 2, 113-120

[3] Lange K.: Handbook of Metal Forming. McGraw-Hill Book Copr., New York, 1985

[4] SińczakJ. (red): Procesy przeróbki plastycznej. Akapit, Kraków, 2003

[5] SińczakJ., KusiakJ., Eapkowski W., Okoń R.: The influence of deformation conditions on the flow of strain rate sensitive materials. Journal of Materials Processing Technology, 34 (1992), 219-224

[6] Stefańska-Kądziela M., Majta J., Muszka K.: Wpływ prędkości odkształcenia na umocnienie stali niskowęglowych i mikrostopowych. Mat. konf. FiMMPOP Warszawa 2005, PW MECHANIKA nr 207

[7] Szczepanik S., Piatkowska K., Franzke M.: Modelowanie numeryczne i fizyczne wyciskania współbieżnego. Mat. konf. FiMMPOP Warszawa 2005, PW MECHANIKA nr 207, 139-144

[8] Lapovok R.Ye., Barnett M.R., Davies C.H.J.: Construction of extrusion limit diagram for AZ31 magnesium alloy by FE simulation. Journal of Materials Processing Technology, 146 (2004), 408-414

[9] Xing H.L., Wang C.W., Zhang K.F., Wang Z.R.: Recent development in the mechanics of superplasticity and its applications. Journal of Materials Processing Technology, 151 (2004), 196-202 